\title{
MODIFICATION IN STRUCTURAL, MORPHOLOGICAL, MAGNETIC AND FERROELECTRIC PROPERTIES OF CALCIUM-DOPED BISMUTH FERRITE NANOPARTICLES
}

\author{
Nushrat Naushin $^{1}$, Sadi Md. Shahriar ${ }^{1 *}$, Oishy Roy ${ }^{2}$ and Ahmed Sharif ${ }^{2}$ \\ ${ }^{I}$ Department of Materials Science \& Engineering, Khulna University of Engineering \& Technology, Khulna \\ ${ }^{2}$ Department of Materials \& Metallurgical Engineering, Bangladesh University of Engineering \& Technology
}

Received: 22 December 2019

Accepted: 30 May 2020

\begin{abstract}
The structural, morphological, magnetic and ferroelectric properties of calcium (Ca) doped bismuth ferrite (BFO) synthesized using a sol-gel method were studied. X-ray diffraction (XRD) analysis followed by Rietveld refinement revealed the lattice distortion of BFO after doping with $6 \%$ and $8 \%$ Ca. This also led to the reduction in particle size by creating oxygen vacancies, which was observed from the surface morphology using Field Emission Scanning Electron Microscopy (FESEM). The Magnetic properties exhibited some enhancements in saturation magnetization when the particle size was near a limiting value. The reduction in the coercive magnetic field with the increase in dopant concentration was also evident from the $M$-H hysteresis loop measured by Vibrating Sample Magnetometer (VSM). The Ferroelectric P-E hysteresis loop exhibited an increased symmetry in the hysteresis loop and increase in the polarization with the increase in $\% \mathrm{Ca}$. The $8 \% \mathrm{Ca}$ doped BFO exhibited an incomplete saturation in the hysteresis loop and was evident to exhibit leakage current characteristics.
\end{abstract}

Keywords: Multiferroic; Nanoparticles; Morphology; XRD; Rietveld refinement; Hysteresis loop.

\section{INTRODUCTION}

Multiferroic materials, exhibiting a combination of ferroelectric and ferromagnetic propertiessimultaneously, have been the subject of extensive research in recent years due to their unique physics which is suitable for potential applications in sensors, transducers, spintronics, data storage, quantum electromagnets, and electric field-controlled ferromagnetic resonance deviceetc (Fiebig et al., 2002; Kimura et al., 2003; Cheong et al., 2007; Martin et al., 2008; Catalan et al., 2009; Wang et al., 2009). Single-phase multiferroic materials such as $\mathrm{TbMnO}_{3}, \mathrm{YMnO}_{3}, \mathrm{BiMnO}_{3}$ and $\mathrm{BiFeO}_{3}$ have been the focus of the most studies in the last few decades (Seshadri et al., 2001; Wang et al., 2003; Van Aken et al., 2004; Xiang et al., 2008; Cheng et al., 2016; Manz et al., 2016; Zhai et al., 2017; Sayedaghaee et al., 2019). Among these studies, $\mathrm{BiFeO}_{3}$ (BFO) is the only room temperature single-phase multiferroic (Ramesh 2014) and has a rhombohedral unit cell (space group R3c) in which two distorted perovskite cells are linked along a pseudo-cubic [111] direction. BFO has sparked a deal of interest in recent times because it's Curie temperature and Néel temperature are $\sim 1103 \mathrm{~K}$ and $643 \mathrm{~K}$, respectively, enabling it to display both ferroelectricity and G-type antiferromagnetism at room temperature so that room temperature applications are possible (Sosnowska et al., 1982; Ederer and Spaldin, 2005; Qi et al., 2005; Han et al., 2014). The lone pair ( $\mathrm{s}^{2}$ orbital) of $\mathrm{Bi}^{3+}$ and local spin ordering of $\mathrm{Fe}^{3+}$ induce the polarization and antiferromagnetism of $\mathrm{BFO}$, respectively. Hence, the $\mathrm{A}$-site $\left(\mathrm{Bi}^{3+}\right)$ contributes mostly to the polarization, while the magnetization results from the $\mathrm{B}$-site $\left(\mathrm{Fe}^{3+}\right)$. However, pure $\mathrm{BFO}$ is unfeasible for multifunctional applications owing to its poor electrical and magnetic properties which arise from a large leakage current, impurity phases such as $\mathrm{Bi}_{25} \mathrm{FeO}_{39}$ and $\mathrm{Bi}_{2} \mathrm{Fe}_{4} \mathrm{O}_{9}$, and weak magnetoelectric coupling (Kumar and Kar, 2000; Gautam et al., 2011; Bhushan et al., 2012). During conventional processing of this material, it is difficult to obtain larger magnetoelectrics due to the volatilization of $\mathrm{A}$-site $\mathrm{Bi}^{3+}$, as the existence of the pure phase of $\mathrm{BiFeO}_{3}$ delays the conversion of $\mathrm{Fe}^{3+}$ into $\mathrm{Fe}^{2+}$. This may be due to the presence of an oxygen vacancy, which is the cause of leakage current (Lin et al., 2018).

To overcome the limitations of pure BFO, researches have been carried out to enhance its ferroelectric and magnetic properties. Several studies have shown that doping the A-site in BFO with different substituents could result in decrease of oxygen vacancies and improvement of the structure and magnetoelectric properties by suppressing the volatilization of bismuth (Lee et al., 2005; Yuan et al., 2006; Yoneda et al., 2007; Khomchenko et al.,2008; Cheng et al., 2009; Troyanchuk et al., 2009). A-site doping with alkaline-earth ions such as $\mathrm{Ca}^{2+}$ (Catalan et al., 2009; Marzouk et al., 2020; Tahir et al., 2020), $\mathrm{Sr}^{2+}$ (Bhushan et al., 2010; Dhir et al., 2018), $\mathrm{Ba}^{2+}$ (Wang et al., 2006; Soltani et al., 2016; Makhdoom et al., 2019) and rare-earth ions such as $\mathrm{La}^{3+}, \mathrm{Nd}^{3+}$, $\mathrm{Ce}^{3+}$ and $\mathrm{Tb}^{3+}$ (Huang et al., 2006; Wang and Nan, 2008; Yu et al., 2008; Lahmar et al., 2009; Liu et al., 2010; Dai et al., 2016; Koval et al., 2017; Yotburut et al., 2017; Wang et al., 2020) have mainly been studied so far. Substitution of divalent alkaline-earth ions have especially been proven effective in improving the ferroelectric 
and ferromagnetic properties of BFO. Nanoparticles (NPs) of BFO doped with Sr exhibited typical M-H behavior of a ferromagnet with saturation magnetization attained within an applied magnetic field of $10 \mathrm{kOe}$ (Bhushan et al., 2010). Ba-doped BFO NPs also showed a great enhancement on dielectric, optical, and magnetization properties (Chauhan et al., 2013).

In the bulk and film form of BFO, smaller $\mathrm{Ca}^{2+}$ ions with a radius of 0.99 Åhave been widely used to substitute larger $\mathrm{Bi}^{3+}$ ions with a radius of $1.03 \AA$ (Khomchenko et al., 2008; Yang et al., 2009; Masó and West, 2012). According to Maso' and West (2012), variations in the electrical conductivity of Ca-doped bulk BFO occur by several orders of magnitude depending on the oxygen partial pressure during processing. Huang et al. (2011) and Yang et al. (2009) reported that, for BFO thin film, A-site Ca-doping facilitates a transformation to tetragonal phase with higher crystal symmetry, and band filling by the doping could regulate conductor to insulator transition. However, investigations based on Ca-doped BFO NPs are rare. In addition, more than 10 $\mathrm{mol} \%$ dopants were used in most of the works involving Ca-doped BFO. Therefore, we study the effects of the addition of a lower Ca content ( 6 and $8 \mathrm{~mol} \%$ ) on BFO NPs synthesized by sol-gel method in this work.

The motivation of this particular investigation is to perceive whether a small change in the composition can have significant effect in the crystallographic structures, lattice parameters, and the magnetic and ferroelectric properties of BFO. Althoughstudies like that conducted by Chauhan et al. (2016) used similar concentrations of Ca-doping (0 to $20 \%$ with $5 \%$ increment), we utilized a much narrower range of doping concentrations. Besides, ferroelectric analysis is absent in their work. In addition, they used tartaric acid as chelating agent in the sol-gel process whereas we used citric acid.Moreover, the stirring time and rate implemented by them is different from ours. This leads to slight variations in microstructures and properties for the same compositions.

\section{EXPERIMENTAL}

All the samples of pure BFO and Ca-doped $\mathrm{BFO}, \mathrm{Bi}_{1-\mathrm{x}} \mathrm{Ca}_{\mathrm{x}} \mathrm{FeO}_{3}(x=0.06$ and 0.08$)$, were prepared using the sol-gel route. The starting chemicals were Bismuth Nitrate Pentahydrate ( $>99 \%$ pure), Ferric Nitrate Nonahydrate ( $>98 \%$ pure), Calcium nitrate ( $>99 \%$ pure), Citric Acid Monohydrate ( $>99 \%$ pure) and ethylene glycol. All the chemicals were manufactured by Merck, India. Equimolar amounts of the metal nitrate precursors were dissolved in deionized water and 2 molar citric acid was added. $6 \%$ excess wt. bismuth was added to compensate the loss of volatile bismuth while annealing. The mixture was simultaneously heated at $80^{\circ} \mathrm{C}$ and stirred at $450 \mathrm{rpm}$ to form the suspension. The orange suspension is then constantly heated and stirred until the suspension turns brown and then $5 \mathrm{ml}$ ethylene glycol was added as it acts as a homogenizing agent in the sol (Ahmadi et al., 2017). Then the sol gradually turned into brown foamy gel which was eventually burnt out. The gel is then dried at $110^{\circ} \mathrm{C}$ for 16 hours followed by crushing the dried gel into powder using agate mortar and pestle, two different heating cycles were used. At the first one, the powder was then heated at a rate of $5{ }^{\circ} \mathrm{C}$ per minute up to $500{ }^{\circ} \mathrm{C}$, while on the other heating cycle, the maximum temperature was $550^{\circ} \mathrm{C}$. The powder was calcined for two hours followed by furnace cooling. The microstructures of the powdered samples were observed using FESEM (JEOL JSM 7600F) from the Department of Glass and Ceramic Engineering, BUET, Dhaka. For further image analysis, MIPAR software was used. XRD analysis was carried out using PANalytical Empyrean X-Ray Diffractometer system) utilizing a Cu x-ray source (wavelength: $=1.540598 \AA$ and $=1.544426 \AA$ ). For extracting crystallographic information from the obtained XRD data, Rietveld Analysis was performed using X'pertHIGHSCORE Plus. The room temperature magnetic properties were measured using the vibrating sample magnetometer (VSM: EV-9 Microsense). For analyzing the ferroelectric property, the polarization hysteresis was performed at room temperature using a frequency of $100 \mathrm{~Hz}$ and an electric field of $10 \mathrm{kV} / \mathrm{mm}$ with the help of the ferroelectric test system (Radiant Precision Multiferroic). Prior to the test, the powdered samples were compacted in the form of tablets using $0.76 \mathrm{~g}$ of powdered samples using a hand pressing machine. The tablets had a diameter of around $1.2 \mathrm{~cm}$ and a thickness of $1.2 \mathrm{~mm}$. The tablets were then sintered using the same heat treatment cycle as the annealing operation which is the tablets are heated at the rate of $5^{\circ} \mathrm{C} / \mathrm{min}$ and held at $550^{\circ} \mathrm{C}$ for 2 hours followed by furnace cooling. Then both of the surfaces of the tablet were covered with silver paste to create a conductive layer.

\section{RESULTS AND DISCUSSION}

\subsection{Morphological Analysis}

The FESEM micrographs were analyzed using MIPAR software. The observed images shown in Figure 1 exhibited nearly circular powder particles and the particle size increased with increasing the annealing temperature and simultaneously showed a decrease in particle size with the addition of Ca dopant. The reason behind the change in particle size is the creation of oxygen vacancies due to the substitution of $\mathrm{Bi}^{3+} \mathrm{by}^{\mathrm{Ca}^{2+}}$. The defect reaction (Kröger-Vink notation) representing this phenomenon is given by: 


$$
2 \mathrm{Ca}^{2+} \longrightarrow 2 \mathrm{BiFeO}_{3} \longrightarrow 2 \mathrm{Ca}_{B i}^{\prime}+2 \mathrm{Fe}_{\mathrm{Fe}}^{X}+6 \mathrm{O}_{O}^{X}+V_{O}^{\prime \prime}
$$

The following reactions represent the synthesis of $6 \%$ and $8 \%$ Ca doped $\mathrm{BFO}$, respectively:

$$
\begin{aligned}
& 2 \times 0.06 \mathrm{CaO}+0.94 \mathrm{Bi}_{2} \mathrm{O}_{3}+\mathrm{Fe}_{2} \mathrm{O}_{3} \rightarrow 2 \mathrm{Bi}_{0.94} \mathrm{Ca}_{0.06} \mathrm{FeO}_{3} \\
& 2 \times 0.08 \mathrm{CaO}+0.92 \mathrm{Bi}_{2} \mathrm{O}_{3}+\mathrm{Fe}_{2} \mathrm{O}_{3} \rightarrow 2 \mathrm{Bi}_{0.92} \mathrm{Ca}_{0.08} \mathrm{FeO}_{3}
\end{aligned}
$$

The average particle size of $\mathrm{BiFeO}_{3}, \mathrm{Bi}_{0.94} \mathrm{Ca}_{0.06} \mathrm{FeO}_{3}$ and $\mathrm{Bi}_{0.92} \mathrm{Ca}_{0.08} \mathrm{FeO}_{3}$ annealed at $550^{\circ} \mathrm{C}$ were $114.8 \mathrm{~nm}$, $82.57 \mathrm{~nm}$ and $76.4 \mathrm{~nm}$, respectively. And the observed average particle sizes for $\mathrm{BiFeO}_{3}, \mathrm{Bi}_{0.94} \mathrm{Ca}_{0.06} \mathrm{FeO}_{3}$ and $\mathrm{Bi}_{0.92} \mathrm{Ca}_{0.08} \mathrm{FeO}_{3}$ annealed at $500^{\circ} \mathrm{C}$ were $105.6 \mathrm{~nm}, 72.65 \mathrm{~nm}$ and $68.79 \mathrm{~nm}$, respectively. The increase in particle size with increase in annealing temperature can be explained with Ostwald ripening process where the internal stress and lattice distortion result in the change in grain morphology.
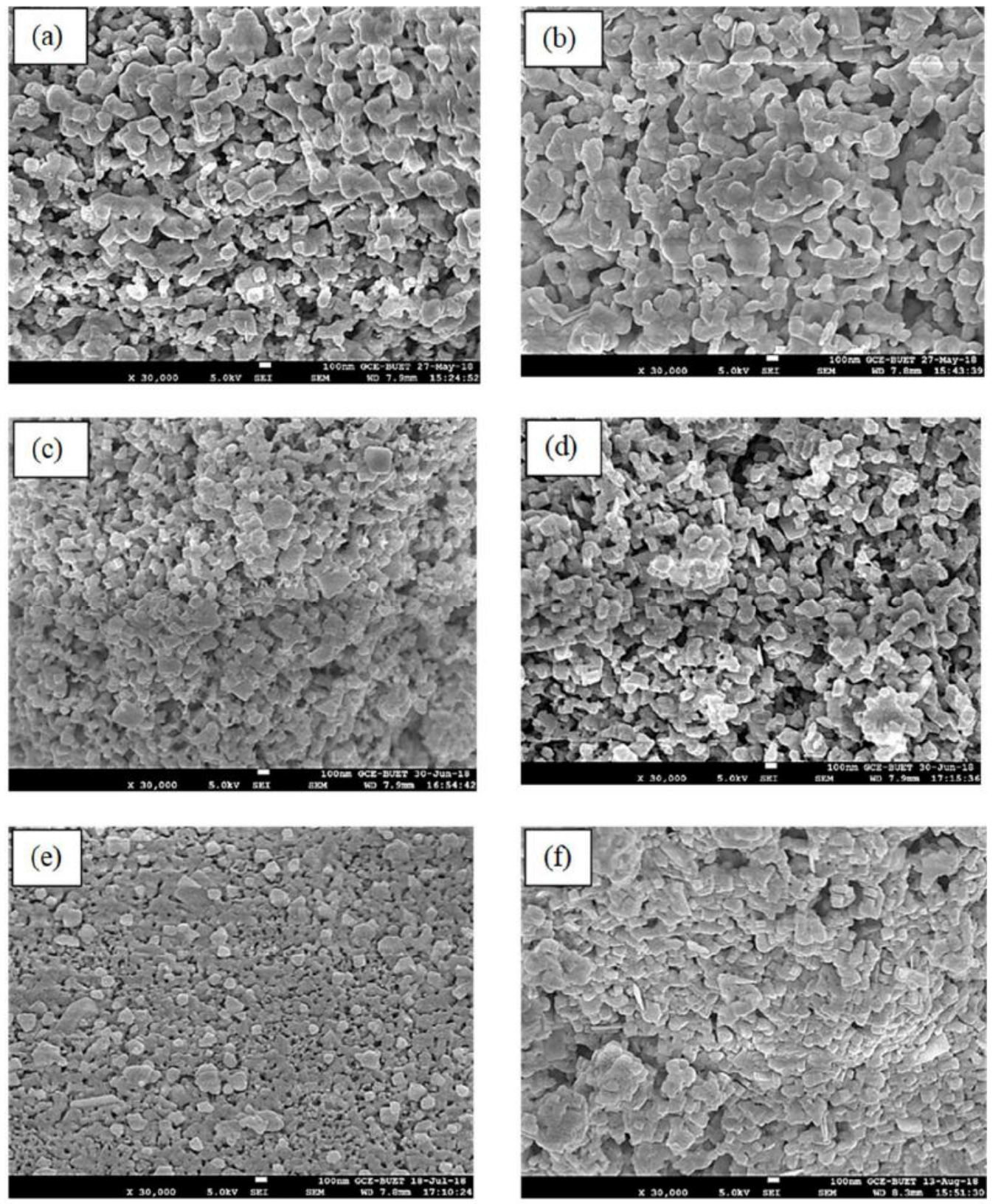

Figure 1: FESEM micrographs of Pure BFO annealed at $500^{\circ} \mathrm{C}$ (a) and $550^{\circ} \mathrm{C} \mathrm{(b);6 \%} \mathrm{Ca} \mathrm{doped} \mathrm{BFO}$ annealed at $500^{\circ} \mathrm{C} \mathrm{(c)} \mathrm{and} 550^{\circ} \mathrm{C}(\mathrm{d}) ; 8 \% \mathrm{Ca}$ doped $\mathrm{BFO}$ annealed at $500^{\circ} \mathrm{C}(\mathrm{e})$ and $550^{\circ} \mathrm{C}$ (f) with a heating cycle including 2 hours of holding time. The magnification of each image is $30,000 \mathrm{X}$. 
The x-ray diffraction analysis results are exhibited in Figure 2(a), while Figure 2(b) represents the magnified XRD pattern at the range of $31-33^{\circ}$. All the patterns exhibited a peak of $\mathrm{Bi}_{2} \mathrm{O}_{3}$ (denoted with a 'star' sign in the pattern). The source of the $\mathrm{Bi}_{2} \mathrm{O}_{3}$ is the additional $\mathrm{Bi}\left(\mathrm{NO}_{3}\right)_{3}$ which was added to prevent the deficiency of Bismuth and creation of non-stoichiometric BFO. From the magnified peaks of all the samples, the peaks for (104) and (110) plane are clearly distinctive in pure BFO, while the peaks are observed to merge into a single peak for the Ca substituted BFO samples. This is because of the distortion of the crystal structure due to the substitution. The Goldschmidt tolerance factor ( $\mathrm{t}$ ) is used to quantify the structural stability of perovskite compounds (Kumar et al., 2014). The tolerance factor is given by:

$$
\mathrm{t}=\frac{\left(<\mathrm{r}_{\mathrm{A}}>+\mathrm{r}_{\mathrm{o}}\right)}{\sqrt{2}\left(<\mathrm{r}_{\mathrm{B}}>+\mathrm{r}_{\mathrm{o}}\right)}
$$

Where, $r_{A}, r_{B}$ and $r_{o}$ are the effective ionic radii of the elements $A, B$ and oxygen, respectively in the $\mathrm{ABO}_{3}$ perovskite compounds. A tolerance factor less than one indicates a compressive strain working on Fe- $\mathrm{O}$ bonds, which means a strain works on the $\mathrm{Bi}-\mathrm{O}$ bond too. And all these induce lattice distortion. The tolerance factor calculated for pure BFO is 0.881163 and for $\mathrm{CaFeO}_{3}$ is 0.870285 . Which means the tolerance factor for the doped samples will be in between 0.881163 and 0.870285 . The doping of the compound induces further distortion which is responsible for the changes in the XRD pattern of pure BFO.
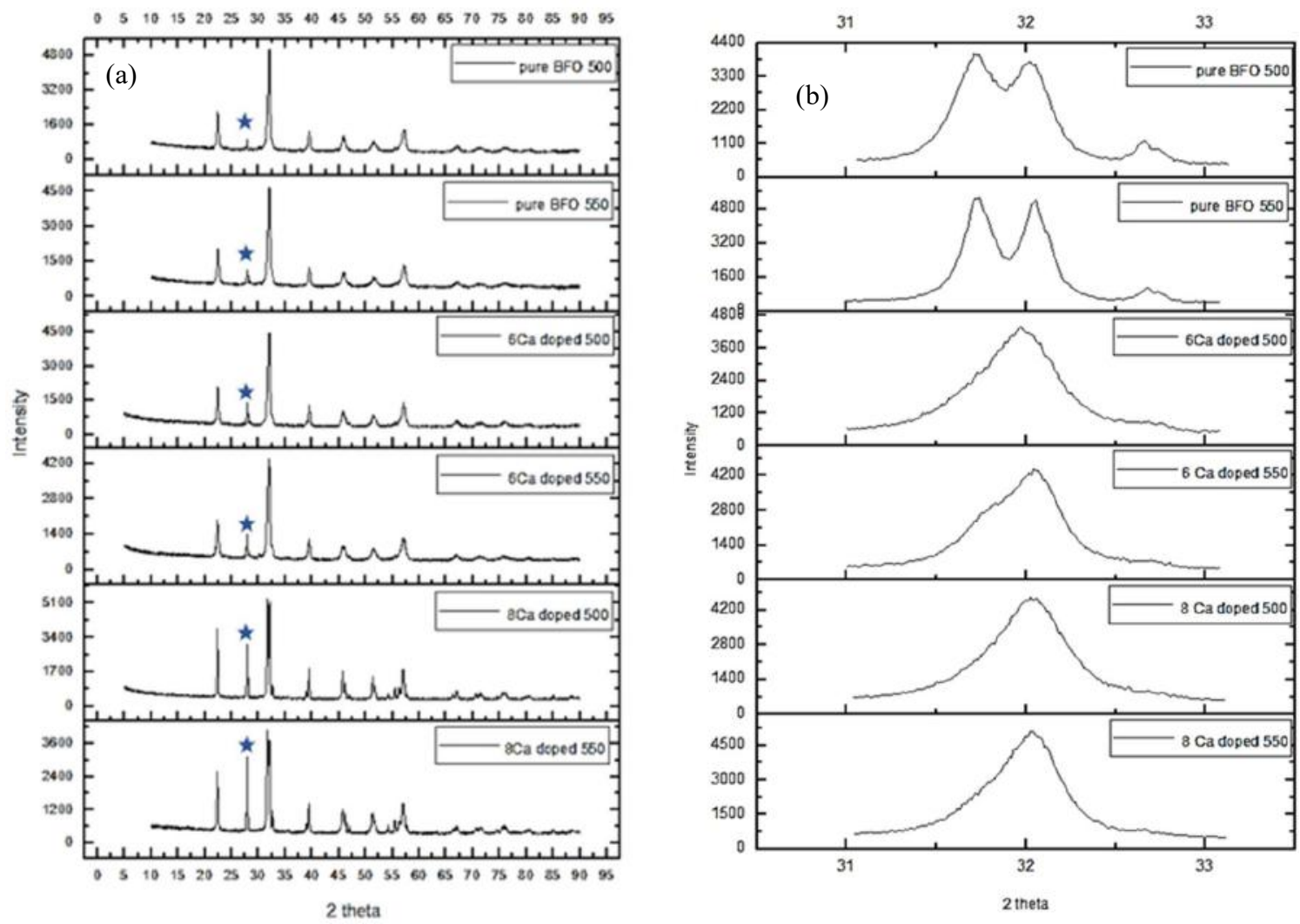

Figure 2: (a) XRD patterns of pure $\left(\mathrm{BiFeO}_{3}\right)$ and $\mathrm{Ca}$ doped Bismuth ferrite $\left[\mathrm{Bi}_{1-\mathrm{x}} \mathrm{Ca}_{\mathrm{x}} \mathrm{FeO}_{3}(x=0.06,0.08)\right]$ annealed at $500^{\circ} \mathrm{C}$ and $550^{\circ} \mathrm{Cwith} 2$ hours holding time; (b) Magnified XRD pattern at the range of $31-32.99^{\circ}$

\subsection{Structural Analysis}

The Rietveld refinement of the XRD data was performed using PANalytical X'pert HIGHSCORE Plus. The R factors and the goodness of fit were determined. From figure 2(b) the pure BFO structure for $\mathrm{x}=0$ clearly represents distorted rhombohedral phase in hexagonal structure exposed by the peak position in $2 \theta \sim 31$ to $33^{\circ}$. It is also observed that the rhombohedral phase peaks get attenuated and shrunk due to Ca-doping in BFO up to $\mathrm{x}=0.06$ and 0.08 , and are almost diminished. The goodness of fit is between 1.11 and 1.25 , which indicates the accuracy of the refinement. It was observed that the substitution of $\mathrm{Bi}^{3+}$ with $\mathrm{Ca}^{2+}$ reduces the overall lattice parameter and the volume of the ceramic. It is because $\mathrm{Ca}^{2+}$ has the effective ionic radius of $100 \mathrm{pm}$ which is lower than the cationic radius of $\mathrm{Bi}^{3+}(103 \mathrm{pm})$. The information obtained from the Rietveld analysis is tabulated in Table 1. 
Table 1: Rietveld refined structural parameters and phases fraction obtained from XRD with $R_{\text {exp }}$ (structure factor), $R_{p}$ (residual for the unweighted pattern), $R_{w}$ (residual for the weighted pattern) and $\chi^{2}$ (goodness of fit) and composition of the $\mathrm{BiFeO}_{3}$ and $\mathrm{Bi}_{1-\mathrm{x}} \mathrm{Ca}_{\mathrm{x}} \mathrm{FeO}_{3}(\mathrm{x}=0.06$ and 0.08 )

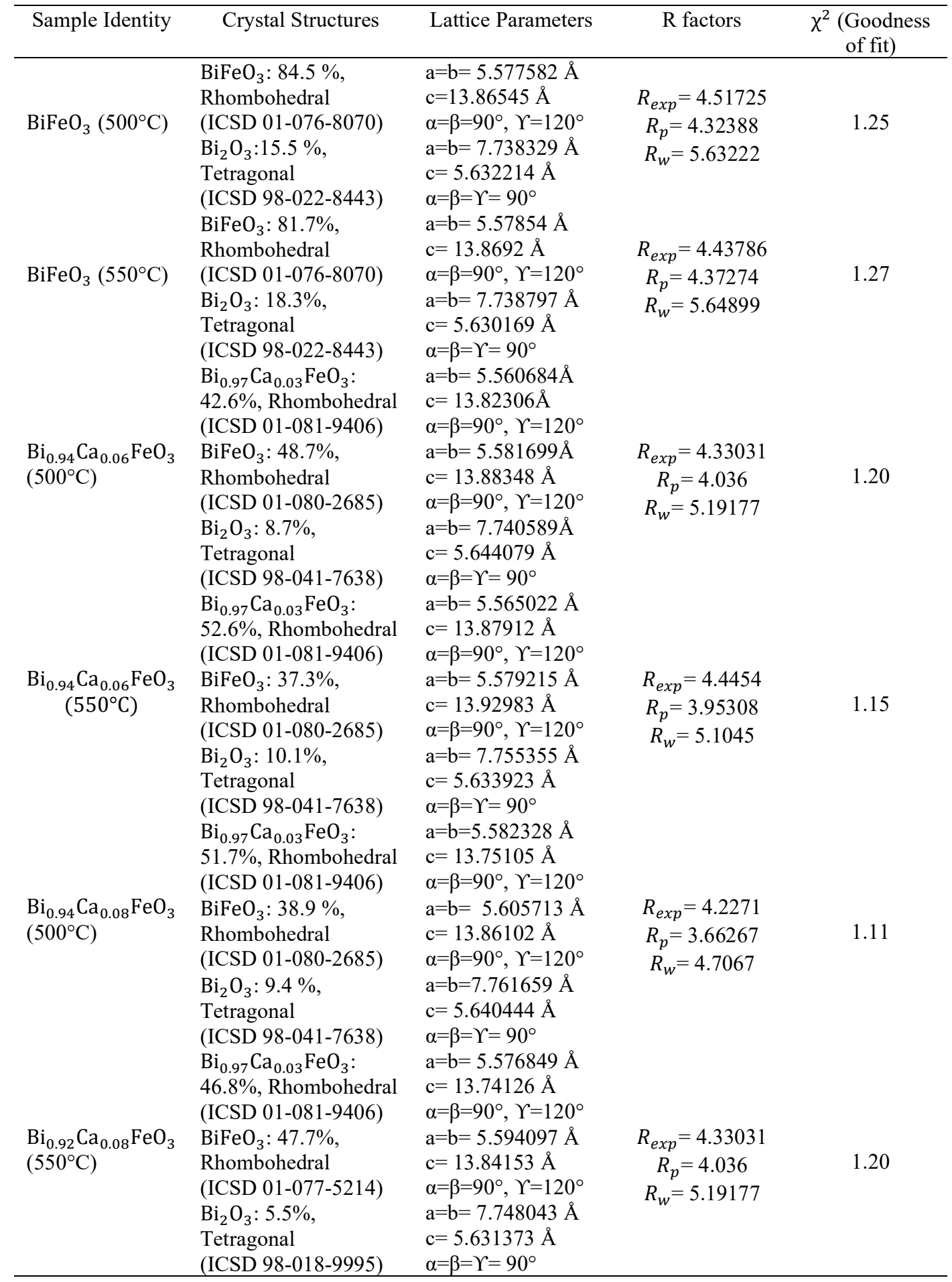

\subsection{Measurement of Magnetization}

VSM: EV-9 Microsense was used to construct the magnetization versus magnetic field diagram for the prepared samples which were annealed at $550^{\circ} \mathrm{C}$ as shown in Figure 3. To know the ferromagnetic effect on $\mathrm{BFO}$ and $\mathrm{Ca}$ 
doped BFO, the full cycle M-H curve was obtained up to a maximum applied field of $10 \mathrm{kOe}$. The remnant magnetization is found to be $0.88 \mathrm{emu} / \mathrm{g}$ for pure $\mathrm{BiFeO}_{3}$. This is due to the fact that $\mathrm{BFO}$ naturally shows antiferromagnetic property which is among few unusual ferromagnetic behaviors. The coercive magnetic field $\left(\mathrm{H}_{\mathrm{c}}\right)$ is observed to decrease with the substitution of $\mathrm{Bi}$ with $\mathrm{Ca}$. The $\mathrm{H}_{\mathrm{c}}$ further decreases with increasing the $\% \mathrm{Ca}$. The remnant magnetization and saturation magnetization are observed to decrease when doped with $6 \%$ $\mathrm{Ca}$, but then increases with increasing the $\% \mathrm{Ca}$. The increase in coercive magnetic field with increasing dopant concentration can be explained from the size reduction in the particles from the SEM micrographs (Pattanayak et al., 2013). According to Wang et al. (2015), magnetic property may increase due to the size effect, as it gives rise to the suppression of spin spiral ordering structure in a condition that the size of the nanoparticle is below the periodicity of spin helical ordering structure $(62 \mathrm{~nm})$. This explains the increase in remnant and saturation magnetization when the $\% \mathrm{Ca}$ increases. It can be depicted from the observed data for pure $\mathrm{BFO}$ and $6 \% \mathrm{Ca}$ doped $\mathrm{BFO}$ that, this effect does not work for a higher size of nanoparticles. The ferromagnetic properties of pure and Ca-doped BFO as determined from the graph manually are summarized in Table 2.

Table 2: Ferromagnetic properties of pure and Ca-doped BFO

\begin{tabular}{cccc}
\hline Sample Identity & $\begin{array}{c}\text { Coercivity } \\
H_{c}(\mathrm{Oe})\end{array}$ & $\begin{array}{c}\text { Remnant Magnetization } \\
M_{r}(\mathrm{emu} / \mathrm{g})\end{array}$ & $\begin{array}{c}\text { Saturation Magnetization } \\
M_{S}(\mathrm{emu} / \mathrm{g})\end{array}$ \\
\hline $\mathrm{BiFeO}_{3}$ & 180.469 & 0.88 & 3.33 \\
$\mathrm{Bi}_{0.94} \mathrm{Ca}_{0.06} \mathrm{FeO}_{3}$ & 122.142 & 0.26 & 1.63 \\
$\mathrm{Bi}_{0.92} \mathrm{Ca}_{0.08} \mathrm{FeO}_{3}$ & 82.89 & 0.23 & 1.997 \\
\hline
\end{tabular}

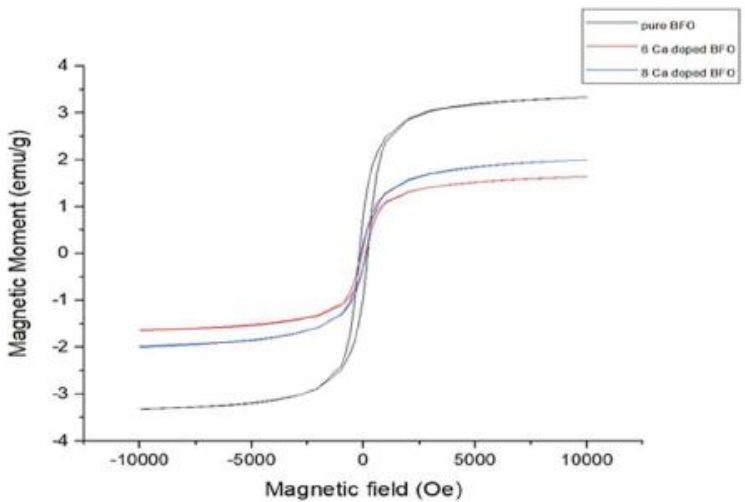

Figure 3: $\mathrm{M}-\mathrm{H}$ curve of $\mathrm{BiFeO}_{3}, \mathrm{Bi}_{0.94} \mathrm{Ca}_{0.06} \mathrm{FeO}_{3}$ and $\mathrm{Bi}_{0.92} \mathrm{Ca}_{0.08} \mathrm{FeO}_{3}$ annealed at $550^{\circ} \mathrm{C}$ for two hours of holding time.

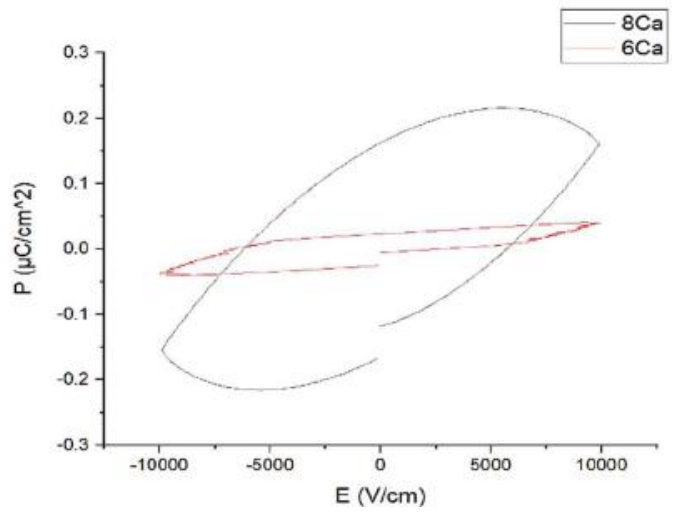

Figure 4: $\mathrm{P}$-E curve of $\mathrm{Bi}_{0.94} \mathrm{Ca}_{0.06} \mathrm{FeO}_{3}$ and $\mathrm{Bi}_{0.92} \mathrm{Ca}_{0.08} \mathrm{FeO}_{3}$ sintered at $550^{\circ} \mathrm{C}$ for two hours of holding time.

\subsection{Ferroelectric Measurement}

The room temperature ferroelectric analysis was performed by Radiant Precision Multimeter using a frequency of $100 \mathrm{~Hz}$ and a maximum applied electric field of $10 \mathrm{kV}$ and the P-E loops are represented in Figure 4. Weak ferroelectric behavior with incomplete saturation was observed for the Ca-doped BFO powders. The P-E hysteresis loopsalso indicate that the leakage current characteristics increase with increasing $\% \mathrm{Ca}$. The remnant polarization $\left(\mathrm{P}_{\mathrm{r}}\right)$ and the saturation polarization $\left(\mathrm{P}_{\mathrm{s}}\right)$ was observed to increase with increasing percentage of doping. On the other hand, the coercive electric field was observed to decrease with increasing amount of dopant. The obtained data is tabulated in Table 3. The displacement of $\mathrm{Bi}$ ion and Fe-O octahedron is responsible for the ferroelectric nature of BFO. $8 \%$ Ca-doped BFO sample displays symmetric P-E hysteresis loops and it implies that, calcium could be responsible for the stabilization of domain walls which interact with vacancies (Costa et al., 2015).

Table 3: Ferroelectric properties of pure and Ca-doped BFO

\begin{tabular}{cccc}
\hline Sample Identity & $\mathrm{E}_{\mathrm{c}}(\mathrm{V} / \mathrm{cm})$ & $\mathrm{P}_{\mathrm{r}}\left(\mu \mathrm{C} / \mathrm{cm}^{2}\right)$ & $\mathrm{P}_{\mathrm{S}}\left(\mu \mathrm{C} / \mathrm{cm}^{2}\right)$ \\
\hline $\mathrm{Bi}_{0.94} \mathrm{Ca}_{0.06} \mathrm{FeO}_{3}$ & 2445.28 & 0.02258 & 0.04126 \\
$\mathrm{Bi}_{0.92} \mathrm{Ca}_{0.08} \mathrm{FeO}_{3}$ & 5654.35 & 0.16299 & 0.21579 \\
\hline
\end{tabular}




\section{CONCLUSIONS}

Pure and Ca doped bismuth ferrite samples were synthesized using the sol-gel route. The XRD results exhibited slight displacement of the peaks due to Ca substitution, which indicate the change in lattice parameters of the samples. Rietveld refinement was conducted to find out the structure parameters and phase compositions of the samples. Since the amount of $\mathrm{Ca}$ substitution was limited to $8 \%$, the substitution did not change the crystal structure. However, addition of excess bismuth nitrate at the initial stage of the process to compensate to the volatilization of Bi from BFO left some bismuth oxide residue in the samples. The FESEM results revealed that the particle size decreases with the substitution of $\mathrm{Bi}$ by $\mathrm{Ca}$ through formation of oxygen vacancies. The reduced particle size also has an effect of the magnetic property. The Ferroelectric P-E hysteresis loops of the Ca doped samples exhibit incomplete saturation of the hysteresis loops. The leakage current characteristics increase with increasing the $\% \mathrm{Ca}$ which indicates towards the reduction in ferroelectric properties of Ca doped $\mathrm{BFO}$.

\section{ACKNOWLEDGEMENTS}

The authors are grateful to the department of Materials and Metallurgical Engineering and the department of Glass and Ceramic Engineering at Bangladesh University of Engineering and Technology, and Atomic Energy Commission, Dhaka Center for providing laboratory facilities to conduct this research.

\section{REFERENCES}

Bhushan, B., Basumallick A., Vasanthacharya N., Kumar S., and Das D., 2010. Sr induced modification of structural, optical and magnetic properties in $\mathrm{Bi}_{1-}{ }_{x} \mathrm{Sr}_{x} \mathrm{FeO}_{3}(\mathrm{x}=0,0.01,0.03,0.05$ and 0.07$)$ multiferroic nanoparticles, Solid State Sci., 12(7), 1063-1069.

Bhushan, B., Das D., Priyam A., Vasanthacharya N., and Kumar S., 2012. Enhancing the magnetic characteristics of $\mathrm{BiFeO}_{3}$ nanoparticles by $\mathrm{Ca}$, Ba co-doping, Mater. Chem. Phys., 135(1), 144-149.

Catalan, G., Sardar K., Church N., Scott J., Harrison R., and Redfern S., 2009. Effect of chemical pressure on the magnetic transition of multiferroic $\mathrm{Ca}-\mathrm{BiFeO}_{3}$, arXiv preprint arXiv:0903.2976.

Catalan, G., and Scott J. F., 2009. Physics and applications of bismuth ferrite, Adv. Mater., 21(24), 2463-2485.

Chauhan, S., Arora M., Sati P., Chhoker S., Katyal S., and Kumar M., 2013. Structural, vibrational, optical, magnetic and dielectric properties of $\mathrm{Bi}_{1-}{ }_{x} \mathrm{Ba}_{x} \mathrm{FeO}_{3}$ nanoparticles, Ceram. Int., 39(6), 6399-6405.

Chauhan, S., Kumar M., Chhoker S., Katyal S., and Singh M., 2016. Substitution driven structural and magnetic transformation in Ca-doped $\mathrm{BiFeO}_{3}$ nanoparticles, RSC advances, 6(49), 43080-43090.

Cheng, C.-J., Kan D., Lim S.-H., McKenzie W., Munroe P., Salamanca-Riba L., Withers R., Takeuchi I., and Nagarajan V., 2009. Structural transitions and complex domain structures across a ferroelectric-toantiferroelectric phase boundary in epitaxial $\mathrm{Sm}$-doped $\mathrm{BiFeO}_{3}$ thin films, Physical Review $\mathrm{B}, \mathbf{8 0}(1)$, 01410.

Cheng, S., Li M., Deng S., Bao S., Tang P., Duan W., Ma J., Nan C., and Zhu J., 2016. Manipulation of magnetic properties by oxygen vacancies in multiferroic $\mathrm{YMnO}_{3}$, Adv. Funct. Mater., 26(21): 35893598.

Cheong, S.-W., and Mostovoy M., 2007. Multiferroics: a magnetic twist for ferroelectricity, Nature materials, 6(1),13

Costa, L., Rocha L., Cortés J., Ramirez M., Longo E., and Simões A., 2015. Enhancement of ferromagnetic and ferroelectric properties in calcium doped $\mathrm{BiFeO}_{3}$ by chemical synthesis, Ceram. Int., 41(8), 9265-9275.

Dai, H., Li T., Chen Z., Liu D., Xue R., Zhao C., Liu H., and Huang N., 2016. Studies on the structural, electrical and magnetic properties of Ce-doped $\mathrm{BiFeO}_{3}$ ceramics, J. Alloys Compd., 672, 182-189.

Dhir, G., Uniyal P., and Verma N., 2018. Multiferroic properties of Sr-doped $\mathrm{BiFeO}_{3}$ nanoparticles, Physica B: Condensed Matter, 531, 51-57.

Ederer, C., and Spaldin N. A., 2005. Weak ferromagnetism and magnetoelectric coupling in bismuth ferrite, Physical Review B, 71(6), 060401.

Fiebig, M., Lottermoser T., Fröhlich D., Goltsev A. V., and Pisarev R. V., 2002. Observation of coupled magnetic and electric domains, Nature, 419(6909), 818.

Gautam, A., Singh K., Sen K., Kotnala R., and Singh M., 2011. Crystal structure and magnetic property of Nd doped $\mathrm{BiFeO}_{3}$ nanocrytallites, Mater. Lett., 65(4), 591-594.

Han, Y., Mao W., Quan C., Wang X., Yang J., Yang T., Li X. A., and Huang W., 2014. Enhancement of magnetic and ferroelectric properties of $\mathrm{BiFeO}_{3}$ by Er and transition element (Mn, Co) co-doping, Materials Science and Engineering: B, 188, 26-30.

Huang, F., Lu X., Lin W., Wu X., Kan Y., and Zhu J., 2006. Effect of Nd dopant on magnetic and electric properties of $\mathrm{BiFeO}_{3}$ thin films prepared by metal organic deposition method, Appl. Phys. Lett., 89(24), 242914.

Huang, J.-Z., Shen Y., Li M., and Nan C.-W., 2011. Structural transitions and enhanced ferroelectricity in Ca and $\mathrm{Mn}$ co-doped $\mathrm{BiFeO}_{3}$ thin films, J. Appl. Phys., 110(9), 094106. 
Khomchenko, V., Kiselev D., Vieira J., Jian L., Kholkin A., Lopes A., Pogorelov Y., Araujo J., and Maglione M., 2008. Effect of diamagnetic $\mathrm{Ca}, \mathrm{Sr}, \mathrm{Pb}$, and $\mathrm{Ba}$ substitution on the crystal structure and multiferroic properties of the $\mathrm{BiFeO}_{3}$ perovskite, J. Appl. Phys, 103(2), 024105.

Khomchenko, V., Kopcewicz M., Lopes A., Pogorelov Y., Araujo J., Vieira J., and Kholkin A., 2008. Intrinsic nature of the magnetization enhancement in heterovalently doped $\mathrm{Bi}_{1-} \mathrm{A}_{\mathrm{x}} \mathrm{FeO}_{3}(\mathrm{~A}=\mathrm{Ca}, \mathrm{Sr}, \mathrm{Pb}, \mathrm{Ba})$ multiferroics, J. Phys. D: Appl. Phys., 41(10), 102003.

Kimura, T., Goto T., Shintani H., Ishizaka K., Arima T.-H., and Tokura Y., 2003. Magnetic control of ferroelectric polarization, nature, 426(6962), 55.

Koval, V., Skorvanek I., Durisin J., Viola G., Kovalcikova A., Svec P., Saksl K., and Yan H., 2017. Terbiuminduced phase transitions and weak ferromagnetism in multiferroic bismuth ferrite ceramics, Journal of Materials Chemistry C, 5(10), 2669-2685.

Kumar, M. M., Palkar V., Srinivas K., and Suryanarayana S., 2000. Ferroelectricity in a pure $\mathrm{BiFeO}_{3}$ ceramic, Appl. Phys. Lett., 76(19), 2764-2766.

Kumar, P., and Kar M., 2014. Effect of Structural Transition on Magnetic Properties of Ca and Mn cosubstituted $\mathrm{BiFeO}_{3}$ Ceramics, arXiv preprint arXiv:1401.4059.

Lahmar, A., Habouti S., Dietze M., Solterbeck C.-H., and Es-Souni M., 2009. Effects of rare earth manganites on structural, ferroelectric, and magnetic properties of $\mathrm{BiFeO}_{3}$ thin films, Appl. Phys. Lett., 94(1), 012903

Lee, D., Kim M. G., Ryu S., Jang H. M., and Lee S. G., 2005. Epitaxially grown La-modified $\mathrm{BiFeO}_{3}$ magnetoferroelectric thin films, Appl. Phys. Lett., 86(22), 222903.

Lin, J., Guo Z., Li M., Lin Q., Huang K., and He Y., 2018. Magnetic and dielectric properties of Ca-substituted $\mathrm{BiFeO}_{3}$ nanoferrites by the sol-gel method, J. Appl. Biomater. Funct. Mater.,16(1_suppl), 93-100.

Liu, J., Li M., Pei L., Wang J., Yu B., Wang X., and Zhao X., 2010. Structural and multiferroic properties of the Ce-doped $\mathrm{BiFeO}_{3}$ thin films, J. Alloys Compd., 493(1-2), 544-548.

Makhdoom, A., Shah S. M., Mahmood T., Iqbal M. J., Akhtar M., and Rafiq M., 2019. Enhancement of ferromagnetism by suppression of spiral spin structure in $\mathrm{Ba}$ doped $\mathrm{BiFeO}_{3}$, J. Magn. Magn. Mater., 484, 286-290.

Manz, S., Matsubara M., Lottermoser T., Büchi J., Iyama A., Kimura T., Meier D., and Fiebig M., 2016. Reversible optical switching of antiferromagnetism in $\mathrm{TbMnO}_{3}$, Nature Photonics, 10(10), 653.

Martin, L., Crane S., Chu Y., Holcomb M., Gajek M., Huijben M., Yang C.-H., Balke N., and Ramesh R., 2008. Multiferroics and magnetoelectrics: thin films and nanostructures, J. Phys.: Condens. Matter, 20(43), 43422

Marzouk, M., Hashem H., Soltan S., and Ramadan A., 2020. Room temperature ferromagnetism driven by Cadoped $\mathrm{BiFeO}_{3}$ multiferroic functional material, Journal of Materials Science: Materials in Electronics, $1-9$.

Masó, N., and West A. R., 2012. Electrical properties of Ca-doped $\mathrm{BiFeO}_{3}$ ceramics: from p-type semiconduction to oxide-ion conduction, Chem. Mater., 24(11), 2127-2132.

Pattanayak, S., Choudhary R., Shannigrahi S., Das P. R., and Padhee R., 2013. Ferroelectric and ferromagnetic properties of Gd-modified $\mathrm{BiFeO}_{3}$, J. Magn. Magn. Mater., 341, 158-164.

Qi, X., Dho J., Tomov R., Blamire M. G., and MacManus-Driscoll J. L., 2005. Greatly reduced leakage current and conduction mechanism in aliovalent-ion-doped $\mathrm{BiFeO}_{3}$, Appl. Phys. Lett., 86(6), 062903.

Ramesh, R., 2014. Electric field control of ferromagnetism using multi-ferroics: the bismuth ferrite story,Philos. Trans. Royal Soc. A, 372(2009), 20120437.

Sayedaghaee, S. O., Xu B., Prosandeev S., Paillard C., and Bellaiche L.,2019. Novel dynamical magnetoelectric effects in multiferroic $\mathrm{BiFeO}_{3}$, Phys. Rev. Lett., 122(9), 097601.

Seshadri, R., and Hill N. A., 2001. Visualizing the role of Bi 6s "lone pairs" in the off-center distortion in ferromagnetic $\mathrm{BiMnO}_{3}$, Chem. Mater., 13(9), 2892-2899.

Soltani, T., and Lee B.-K., 2016. Novel and facile synthesis of Ba-doped $\mathrm{BiFeO}_{3}$ nanoparticles and enhancement of their magnetic and photocatalytic activities for complete degradation of benzene in aqueous solution, J. Hazard. Mater., 316, 122-133.

Sosnowska, I., Neumaier T. P., and Steichele E., 1982. Spiral magnetic ordering in bismuth ferrite, Journal of Physics C: Solid State Physics, 15(23), 4835.

Tahir, M., Riaz S., Khan U., Hussain S. S., Nairan A., Akbar A., Saleem M., Atiq S., and Naseem S., 2020. Enhanced structural and magnetic ordering in as-synthesized $\mathrm{Ca}$ doped bismuth iron oxide nanoceramics, J. Alloys Compd., 832, 154725.

Troyanchuk, I., Bushinsky M., Karpinsky D., Mantytskaya O., Fedotova V., and Prochnenko O., 2009. Structural transformations and magnetic properties of $\mathrm{Bi}_{1-\mathrm{x}} \mathrm{Ln}_{\mathrm{x}} \mathrm{FeO}_{3}(\mathrm{Ln}=\mathrm{La}, \mathrm{Nd}, \mathrm{Eu})$ multiferroics, physica status solidi (b), 246(8), 1901-1907.

Van Aken, B. B., Palstra T. T., Filippetti A., and Spaldin N. A., 2004. The origin of ferroelectricity in magnetoelectric $\mathrm{YMnO}_{3}$, Nature materials, 3(3), 164. 
Wang, D., Goh W., Ning M., and Ong C., 2006. Effect of Ba doping on magnetic, ferroelectric, and magnetoelectric properties in mutiferroic $\mathrm{BiFeO}_{3}$ at room temperature, Appl. Phys. Lett., 88(21), 212907.

Wang, J., Neaton J., Zheng H., Nagarajan V., Ogale S., Liu B., Viehland D., Vaithyanathan V., Schlom D., and Waghmare U., 2003. Epitaxial $\mathrm{BiFeO}_{3}$ multiferroic thin film heterostructures, Science, 299(5613), 1719-1722.

Wang, K., Liu J.-M., and Ren Z., 2009. Multiferroicity: the coupling between magnetic and polarization orders, Adv. Phys., 58(4), 321-448.

Wang, T., Wang X.-L., Song S.-H., and Ma Q., 2020. Effect of rare-earth $\mathrm{Nd} / \mathrm{Sm}$ doping on the structural and multiferroic properties of $\mathrm{BiFeO}_{3}$ ceramics prepared by spark plasma sintering, Ceram. Int.

Wang, X., Wang S., Liu W., Xi X., Zhang H., Guo F., Xu X., Li M., Liu L., and Zhang C., 2015. Novel electrical conductivity properties in $\mathrm{Ca}$-doped $\mathrm{BiFeO}_{3}$ nanoparticles, J. Nanopart. Res., 17(5), 209.

Wang, Y., and Nan C.-W.,2008. Effect of Tb doping on electric and magnetic behavior of $\mathrm{BiFeO}_{3}$ thin films, J. Appl. Phys., 103(2), 024103.

Xiang, H., Wei S.-H., Whangbo M.-H., and Da Silva J. L., 2008. Spin-orbit coupling and ion displacements in multiferroic $\mathrm{TbMnO}_{3}$, Phys. Rev. Lett., 101(3), 037209.

Yang, C.-H., Seidel J., Kim S., Rossen P., Yu P., Gajek M., Chu Y.-H., Martin L. W., Holcomb M., and He Q., 2009. Electric modulation of conduction in multiferroic Ca-doped $\mathrm{BiFeO}_{3}$ films, Nature materials, 8(6), 485.

Yoneda, Y., Yoshii K., Saitoh H., and Mizuki J., 2007. Magnetic and Ferroelectric Properties of $\left(\mathrm{Bi}_{1-}{ }_{\mathrm{x}} \mathrm{La}_{\mathrm{x}}\right)$ $\mathrm{FeO}_{3}$, Ferroelectrics, 348(1), 33-37.

Yotburut, B., Thongbai P., Yamwong T., and Maensiri S., 2017. Electrical and nonlinear current-voltage characteristics of La-doped $\mathrm{BiFeO}_{3}$ ceramics, Ceram. Int., 43(7), 5616-5627.

Yu, B., Li M., Liu J., Guo D., Pei L., and Zhao X., 2008. Effects of ion doping at different sites on electrical properties of multiferroic $\mathrm{BiFeO}_{3}$ ceramics, J. Phys. D: Appl. Phys., 41(6): 065003.

Yuan, G., Or S. W., Liu J., and Liu Z., 2006. Structural transformation and ferroelectromagnetic behavior in single-phase $\mathrm{Bi}_{1-x} \mathrm{Nd}_{\mathrm{x}} \mathrm{FeO}_{3}$ multiferroic ceramics, Appl. Phys. Lett., 89(5), 052905.

Zhai, L.-J., and Wang H.-Y., 2017. The magnetic and multiferroic properties in $\mathrm{BiMnO}_{3}$, J. Magn. Magn. Mater., 426, 188-194. 